\title{
Influência da infecção viral no processo de reparo das lesões periapicais: uma revisão
}

\section{narrativa}

Influence of viral infection in the healing process of periapical lesions: a narrative review

Influencia de la infección viral en el proceso de reparación de lesiones periapicales: una revisión narrativa

ORCID: https://orcid.org/0000-0003-4313-7149 Universidade Estadual Paulista, Brasil

E-mail: cristiane.cantiga@unesp.br

Rogério de Castilho Jacinto

ORCID: https://orcid.org/0000-0002-2362-8920 Universidade Estadual Paulista, Brasil

E-mail: rogerio.castilho@unesp.br

Gustavo Sivieri-Araujo

ORCID: https://orcid.org/0000-0002-8402-7408 Universidade Estadual Paulista, Brasil

E-mail: gustavo.sivieri@unesp.br

Cristiane Duque

ORCID: https://orcid.org/0000-0002-2575-279X

Universidade Estadual Paulista, Brasil

E-mail: cristiane.duque@unesp.br

Luciano Tavares Angelo Cintra

ORCID: https://orcid.org/0000-0003-2348-7846 Universidade Estadual Paulista, Brasil E-mail: luciano.cintra@unesp.br

João Eduardo Gomes-Filho

ORCID: https://orcid.org/0000-0001-5994-2287 Universidade Estadual Paulista, Brasil E-mail: joao.eduardo@unesp.br

\begin{abstract}
Resumo
Fundamento: O tratamento endodôntico tem como principal objetivo eliminar os microrganismos e seus produtos tóxicos, permitindo o reestabelecimento das defesas do organismo e consequentemente, o reparo dos tecidos periapicais. No entanto, inúmeros fatores podem afetar o reparo periapical, como os materiais obturadores empregados, a presença de microrganismos, fatores sistêmicos e mais recente, as infecções virais têm sido associadas ao agravamento das lesões periapicais. Objetivo: Discutir a relação das principais infecções virais com as manifestações da periodontite apical e como estas infecções podem influenciar no reparo dos tecidos periapicais. Conclusão: A literatura não estabelece uma relação causa-efeito entre a presença de vírus nos tecidos periapicais e o aumento da patogenicidade da periodontite apical. No entanto, mais estudos devem ser realizados para afirmar o potencial viral nos tecidos periapicais, uma vez que a literatura mostra uma resposta imunológica na periodontite apical desencadeada por vírus na fase lítica, semelhante a observada a outros patógenos, sendo capaz de exacerbar a resposta inflamatória, aumentar a reabsorção óssea e ainda interferir no reparo dos tecidos periapicais.
\end{abstract}

Palavras-chave: Citomegalovírus; Herpes simples; HIV; Periodontite apical; Saúde oral; Vírus Epstein-Barr. 


\begin{abstract}
Background: Endodontic treatment aims to eliminate microorganisms and their toxic products, allowing the reestablishment of the host defenses and consequently, the healing of periapical tissues. However, numerous factors can affect periapical healing, such as the filling materials, the presence of microorganisms, systemic factors and, more recently, viral infections have been associated with the worsening of periapical lesions. Objective: To discuss the relationship between the main viral infections and the manifestations of apical periodontitis and how these infections can influence the repair of periapical tissues. Conclusion: The literature does not establish a cause-effect relationship between the presence of viruses in the periapical tissues and the increase in pathogenicity of the apical periodontitis. However, further studies should be conducted to affirm the viral potential in periapical tissues, since the literature shows an immune response in apical periodontitis triggered by viruses in the lytic phase, similar to that observed in other pathogens, which can exacerbate the inflammatory response, increase bone resorption and also interfere in the healing of periapical tissues.
\end{abstract}

Keywords: Apical periodontitis; Cytomegalovirus; Epstein-Barr Virus; Herpes simplex; HIV; Oral health.

\title{
Resumen
}

Antecedentes: El tratamiento de endodoncia tiene como principal objetivo eliminar los microorganismos y sus productos tóxicos, permitiendo el restablecimiento de las defensas del organismo y consecuentemente, la reparación de los tejidos periapicales. Sin embargo, numerosos factores pueden afectar la reparación periapical, como los materiales de obturación, la presencia de microorganismos, factores sistémicos y más recientemente, las infecciones virales se han asociado al empeoramiento de las lesiones periapicales. Objetivo: Discutir la relación entre las principales infecciones virales y las manifestaciones de la periodontitis apical y cómo estas infecciones pueden influir en la reparación de los tejidos periapicales. Conclusión: La literatura no establece una relación causa-efecto entre la presencia de virus en los tejidos periapicales y el aumento de patogenicidad de la periodontiti apical. Sin embargo, deben realizarse más estudios para afirmar el potencial viral en tejidos periapicales, ya que la literatura muestra una respuesta inmune en periodontitis apical desencadenada por virus en fase lítica, similar a la observada en otros patógenos, pudiendo exacerbar la respuesta inflamatoria, aumentan la resorción ósea y también interfieren con la reparación de los tejidos periapicales.

Palabras clave: Citomegalovirus; Herpes simple; Periodontitis apical; Salud bucal; Virus de Epstein-Barr; VIH.

\section{Introdução}

A periodontite apical é uma doença inflamatória crônica decorrente de um processo infeccioso persistente nos tecidos periapicais, causado principalmente pela colonização de microrganismos no interior do canal radicular (Siqueira \& Rocas, 2008). A composição da microbiota endodôntica inclui fungos, vírus e principalmente bactérias, desencadeando uma resposta imunológica inata e adaptativa mediada por vários metabólitos, o que resulta na inflamação dos tecidos periapicais (Gomes \& Herrera, 2018). A destruição tecidual é a resposta direta entre o combate dos microrganismos e a resposta imune do hospedeiro, que pode estar associada de manifestações clínicas e achados radiográficos (Jakovljevic et al., 2020; Marton \& Kiss, 2014; Slots et al., 2003).

O tratamento endodôntico tem como principal objetivo eliminar os microrganismos e seus produtos tóxicos, permitindo o reestabelecimento das defesas do organismo e consequentemente, favorecendo o reparo dos tecidos periapicais (Ricucci et al., 2009). Um estudo realizado por Holland et al. (2017) mostra inúmeros fatores que podem afetar o reparo dos tecidos periapicais de dentes submetidos ao tratamento endodôntico, dentre eles a execução errada de alguma das etapas da terapia, os materiais obturadores empregados, a presença de microrganismos e fatores sistêmicos como, diabetes e hipertensão (Holland et al., 2017). No entanto, sabemos que as infecções virais estão relacionadas às doenças na cavidade oral, como úlceras, tumores, líquen plano, síndrome de Sjögren e doença periodontal, além de mostrarem associação com o agravamento de algumas lesões (Vigueras et al., 2016).

Desde a década de 60, Shindell (1962) tem sugerido a possível presença de vírus nas lesões periapicais, porém, Elkins et al. (1994) foi uns dos primeiros a detectar em paciente HIV positivo, com métodos de testes de PCR viral, a presença do vírus HIV em lesões periapicais, abrindo portas para novas investigações relacionando vírus e periodontite apical. Desde então, a maioria dos estudos detectou o Citomegalovírus humano (HCMV) em mais de 50\% das lesões periapicais (Sabeti et al. 
2003b; Sabeti et al. 2009; Yazdi et al. 2008). Uma revisão sistemática demonstrou que o vírus Epstein-Barr (EBV) foi detectado somente em 9 estudos, os quais constavam a presença do vírus em mais de 50\% das lesões (Jakovljevic \& Andric, 2014), já em outros estudos também foi detectado a presença de ambos os vírus (Jakovljevic \& Andric, 2014; Jakovljevic et al., 2015). Jakovljevic et al. (2015) realizaram um estudo em que o Citomegalovírus e o Epstein-Barr puderam ser encontrados em lesões periapicais, com incidência de 54\% e 76\% respectivamente, sugerindo que os vírus possuem um papel importante na etiopatogenia das lesões periapicais (Jakovljevic \& Andric, 2014). Além disso, é possível encontrar o citomegalovírus em cistos periapicais e ceratocistos (Vigueras et al., 2016).

A saliva é a principal via de contaminação dos vírus em lesões periapicais e dentes com extensa destruição coronária, assim como a não utilização do isolamento absoluto em tratamentos endodônticos são a porta de entrada de vírus para os canais radiculares (Vigueras et al., 2016). Esta revisão visa discutir a importante relação das principais infecções virais com as manifestações da periodontite apical e como estas infecções podem influenciar no reparo dos tecidos periapicais.

\section{Metodologia}

Trata-se de uma revisão bibliográfica do tipo narrativa, modelo qualitativo, (Pereira et al., 2018; Ludke \& Andre, 2013; Koche, 2011) buscando discutir e compreender melhor a interação entre as manifestações virais e o reparo das lesões periapicais. O tema abordado por essa revisão é relevante, pois trata-se de uma investigação pouco conhecida pelos clínicos e pesquisadores da área devido as limitações e complexidade dos estudos encontrados.

Foram revisados artigos encontrados nas bases de dados PubMed/MEDLINE, SCOPUS e Cochrane Library utilizando as seguintes palavras chaves: "apical periodontitis", "periapical lesion", "endodontic", "virus", "viral infection". O unitermo de escolha foi "AND", para agrupar os assuntos. Os artigos incluídos foram publicados até fevereiro de 2021 com resumo em inglês. Foram definidos os seguintes critérios de inclusão: estudos clínicos e animais que avaliaram a influência dos vírus na patogenicidade da periodontite apical e no reparo dos tecidos periapicais durante e após o tratamento endodôntico. Na primeira busca foram incluídos artigos que tinham o título e resumo de acordo com a proposta. Na segunda etapa da seleção todos os artigos foram lidos a fim de verificar quais os vírus mais comuns observados na periodontite apical. A partir desta análise foram incluídos os estudos que abordaram os seguintes vírus: Herpes Vírus, Epstein-Barr Vírus, Citomegalovírus Humano e HIV. Foram excluídos artigos que não apresentaram clareza nos resultados. O resultado da busca e interpretação dos achados foram discutidos por sessões de acordo com a prevalência dos tipos de vírus encontrados associados à periodontite apical. Como suporte metodológicos para definir os critérios de busca, inclusão e exclusão dos estudos foram empregados os estudos de Pereira et al. (2018), Ludke e Andre (2013), Koche (2011) e Duarte et al. (2020), recém-publicado nesse periódico.

\section{Resultados e Discussão}

\subsection{Herpes vírus}

Atualmente podemos encontrar oito espécies de Herpes vírus humano com características biológicas e clínicas distintas descritas na literatura: o Vírus Herpes Simples tipo 1 e 2 (HSV 1-2), Vírus Varicela-Zoster (VZV), Epstein-Barr Vírus, Citomegalovírus humano (HCMV), Herpes vírus humano-6 (HHV-6), Herpes vírus humano-7 (HHV-7) e Herpes vírus humano-8 (HHV-8) (Chen et al., 2020; Ozbek et al., 2016; Slots, 2005). Os Herpes vírus são comuns em humanos, na maioria das vezes sendo inofensivos, mas podem apresentar morbidade e mortalidade significativas em indivíduos imunocomprometidos, como pacientes portadores de HIV (Chen et al., 2020).

O Herpes vírus é formado por 4 camadas estruturais distintas: núcleo nuclear, capsídeo, tecido amorfo e envelope de bicamada lipídica (Chen et al., 2020). A infecção inicial do herpes vírus é seguida por uma fase latente nas células do 
hospedeiro, sendo essa sua principal característica, garantindo com que o vírus sobreviva ao longo da vida no hospedeiro. O VZV e os HSV 1-2 estabelecem o período de latência em células neurais nos gânglios sensoriais do hospedeiro, sendo os fluidos secretores os principais meios de transmissão (Chen et al., 2020; Slots et al., 2003), como a saliva (Vigueras et al., 2016; Slots et al., 2003). O herpes vírus torna-se ativo de forma espontânea ou provocada por infecções concomitantes ao hospedeiro, como febre, uso de fármacos, traumas, estresse emocional e outros fatores que podem alterar a defesa imunológica do hospedeiro (Slots et al., 2003). Apresenta-se muitas vezes com manifestações faciais e orais, como lábios, olhos e regiões inervadas pelo nervo trigêmeo (Guimarães et al., 2021).

O Herpes vírus (HHV-6) pode contribuir para etiopatogenia da periodontite apical, aumentando a produção de citocinas e quimiocinas na cascata da inflamação, além de aumentar a sintomatologia, por meio de interações sinérgicas bacterianas (Marton \& Kiss, 2014). A infecção do Herpes vírus nos tecidos pulpar e periapicais inicia-se por uma infecção bacteriana ou um trauma mecânico da região, deslocando células inflamatórias infectadas pelo Herpes vírus para regiões pulpo-periapicais (Slots et al., 2003). Segundo a hipótese elaborada por Slots et al. (2003), esses são os principais fatores para a predisposição do Herpes vírus nos tecidos pulpo-periapicais: (1) a presença de herpes vírus em tecidos periapicais; (2) a ativação de herpes vírus periapicais latentes; (3) resposta inadequada de linfócitos T citotóxicos antivirais; (4) presença de bactérias patogênicas e (5) nível insuficiente de anticorpos.

Ozbek et al. (2016) verificaram a presença do Herpes vírus nos processos de abscesso apicais agudos, tendo como resultado cerca de $9 \%$ dos casos com a presença do HPV e HHV-6 em lesões grandes ( $\geq 5 \mathrm{~mm}$ ). Embora o Herpes vírus isolado não apresente potencial para desenvolver processos agudos, há hipóteses que a infecção do vírus concomitante à bacteriana pode contribuir e até mesmo exacerbar a patogênese da periodontite apical (Saygun et al., 2004; Slots, 2005).

Em outro estudo realizado por Ferreira et al. (2011) foram coletadas amostras de 23 abscessos, dentre elas, 14 das amostras (61\%) apresentavam pelo menos um tipo de Herpes vírus. O HHV-8 foi encontrado em 11 das amostras, VZV e HHV-6 em 2, HHV-7 e o HSV 1-2 em uma amostra. Ainda neste estudo, foram detectados 5 casos de associação entre os VZV, HHV-7 e Papilomavírus Humano (HPV), além de 4 amostras que envolviam o HHV-8 em pares com os HSV 1-2, VZV, HHV-6 e com o HPV. Esses dados reforçam a hipótese de Slots (2005) de que os Herpes vírus podem estar associados a processos endodônticos e periodontais agudos.

O estudo de Guilherme et al. (2011) avaliou a associação entre a infecção por Herpes vírus e o resultado do tratamento endodôntico em 72 pacientes, além disso verificou-se a condição sistêmica (tabagismo, diabetes e hipertensão) do paciente. Através da coleta de saliva, detectou-se que $94 \%$ dos pacientes tinham presente algum tipo de Herpes vírus, sendo o HHV-8 o mais prevalente com $86 \%$. O estudo constatou que as condições sistêmicas não interferiram significativamente quando associadas à doença pós-tratamento endodôntico.

Os Herpes vírus podem causar efeitos citopáticos em fibroblastos periapicais, células epiteliais e células ósseas, resultando em alterações da renovação e reparo do tecido (Figura 1). O HHV-6 pode alterar a secreção de interleucina 12, que é um mediador essencial nas respostas antivirais com Th1 (linfócitos de defesa mediada por fagocitose) (Ozbek et al., 2016). O principal receptor do HHV-6 é a glicoproteína CD46, presente em grande parte das células humanas, cuja principal função é proteger as células autólogas do complemento (Ozbek et al., 2016; Slots et al., 2003).

$\mathrm{Na}$ periodontia tem se discutido o sinergismo entre os Herpes vírus e bactérias, acreditando que esta interação seja capaz de contribuir separadamente ou reciprocamente com o avanço da doença periodontal, e quando atuam de maneira sinérgica podem agravar a doença, principalmente em casos de pacientes sistemicamente comprometidos (Chen et al., 2020). Apesar de estudos na endodontia afirmarem o sinergismo entre bactéria-vírus (Marton \& Kiss, 2014; Sabeti et al., 2003a; Sabeti et al., 2003b), ainda há poucas evidências na literatura. 
Figura 1. Imagem adaptada de Slots et al. (2003): modelo hipotético do papel das espécies do Herpes vírus no desenvolvimento da periodontite apical.

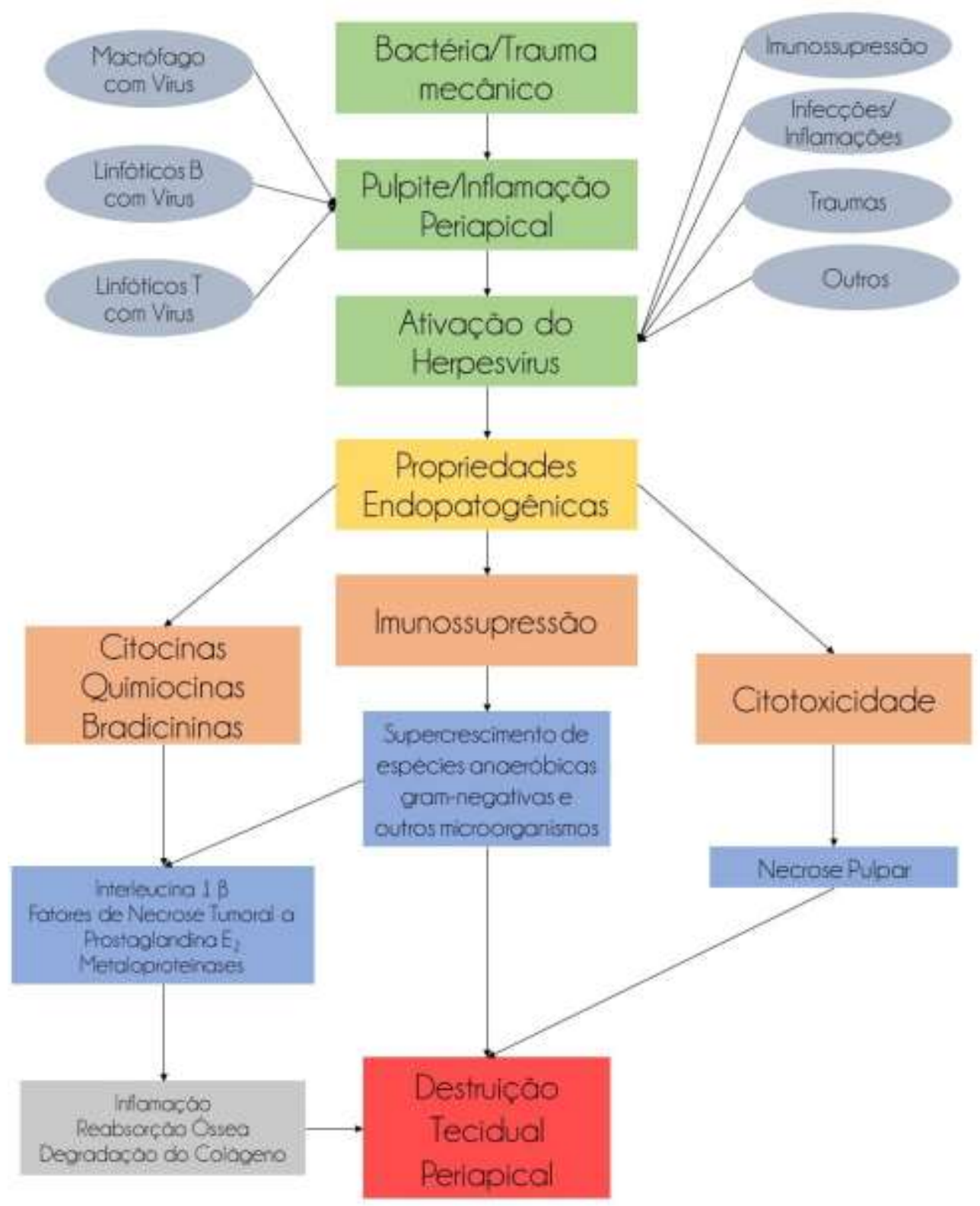

Fonte: Autores.

\subsection{Epstein-Barr Vírus}

O vírus Epstein-Barr é um Herpes-vírus humano descoberto pela primeira vez em linfoblastos de pacientes com Linfoma de Burkitt (Epstein et al., 1964). Mais de 90\% das pessoas em todo o mundo estão infectadas com o EBV, sendo que a exposição ao vírus normalmente ocorre no início da vida, com a maioria das crianças tornando-se soropositivo aos 5 anos de idade (Cohen, 2000). A condição socioeconômica favorece a infecção e manifestação viral, visto que em áreas com maior desenvolvimento o período de latência viral pode ocorrer por toda vida, ao contrário do que se observa em populações de menor desenvolvimento, sendo os adultos uniformemente positivos (Green \& Michaels, 2013).

O EBV é mais comumente transmitido por contato de secreções do aparelho respiratório, que promove o acesso e a entrada de células reticuloendoteliais à via respiratória. A infecção faríngea é seguida pela disseminação do vírus por todo o corpo, com os linfócitos B sendo alvo principal. A resposta imunológica à infecção aumenta de forma constante com expansão 
de clones de células $\mathrm{T}$ citolíticas específicas para EBV, eventualmente reconhecendo e controlando a infecção primária (Nowalk \& Green, 2016). A mononucleose infecciosa é causada pela infecção por EBV (Luzuriaga \& Sullivan, 2010). Sintomas malignos, como linfoma de Burkitt, linfoma de Hodgkin e linfoma de células T estão associados ao EBV (Jones et al., 1988; Mochanko et al., 1979), além disso é um vírus importante não apenas em doenças malignas, mas também em doenças sistêmicas e inflamação local pelo potencial de acometer doenças autoimunes como a artrite reumatoide (Sawada et al., 2007) e a síndrome de Sjögren (Kivity et al., 2014).

Os sintomas de infecção por EBV variam de acordo com a idade e o estado imunológico do paciente. A maioria das infecções em crianças são benignas e frequentemente subclínica (Cohen, 2000). Neste grupo, é mais frequente a manifestação aguda da infecção representada por febre e doença respiratória superior, que não é distinguível de gripes. Adultos jovens que sofrem infecção primária por EBV têm maior probabilidade de apresentar achados clássicos de mononucleose infecciosa (Nowalk \& Green, 2016).

O EBV permanece latente após a infecção e não exibe patogenicidade imediata. As proteínas latentes da membrana do EBV (LMPs) são semelhantes aos receptores da superfamília do receptor do fator de necrose tumoral (TNF- $\alpha$ ) e podem ativar vias de sinalização imunológica para a produção de várias citocinas (Jangra et al., 2019). A replicação lítica do EBV, ciclo em que o vírus insere seu material genético na célula hospedeira e passa a dominar o metabolismo até sua replicação, induz reação inflamatória envolvendo a expressão de interleucina $-1 \beta$ (IL-1 $\beta$ ), antagonista do receptor de IL-1, IL-6, IL-8, IL-18, TNF- $\alpha$, IFN- $\alpha$ / $\beta$, IFN- $\gamma$, monocina induzida por IFN- $\gamma$, proteína 10 induzível por IFN- $\gamma$ e fator estimulador de colônia de granulócitos-macrófagos (Mogensen \& Paludan, 2001).

Dentre os subtipos do Herpes-vírus, o EBV é o mais encontrado em lesões periapicais, prevalente também em granulomas periapicais. Sabeti et al. (2012) relataram que o EBV estava presente em 8 de 9 lesões periapicais sintomáticas, o que revelou uma correlação direta entre a presença do vírus e o aumento das citocinas TNF- $\alpha$, IFN- $\gamma$, IL-1, IL-6 e IL-12. O aumento de estresse oxidativo e reguladores de reabsorção óssea também estão relacionados com a presença do EBV nas lesões (Jakovljevic et al., 2018).

Sabeti et al. (2003a) avaliaram lesões periapicais coletadas em cirurgias parendodônticas de dentes hígidos com canais radiculares calcificados, acometidos de lesão periapical sintomática e constataram que todas as lesões apresentavam transcrição do EBV. Os autores acreditam que períodos prolongados de latência do EBV interrompidos por períodos de ativação podem explicar episódios sintomático da doença periapical, bem como justificam que a reativação frequente do vírus pode suportar a agudização da periodontite apical. Por outro lado, os autores enfatizam que a ausência de infecção do EBV ou a não reativação do vírus pode ser a razão pela qual algumas lesões periapicais permanecem clinicamente estáveis por longos períodos (Sabeti et al., 2003a).

O DNA do EBV foi encontrado em pacientes com pulpite irreversível sintomática ou assintomática, periodontite apical primária sintomática e assintomática e ainda em pacientes com periodontite apical previamente tratada, todos em altas porcentagens quando em comparação com espécimes de polpa saudáveis (Li et al., 2009).

Um estudo recente avaliou em lesões periapicais a expressão de mRNA do BZLF-1, gene precoce imediato do EBV, a proteína de latência de membrana 1 (LMP1) e ZEBRA, a proteína lítica precoce do EBV codificada por BZLF-1 revelando que o DNA do EBV e o mRNA do BZLF-1 foram detectados na maioria das lesões periapicais, mas não em tecido gengival saudável. Os autores observaram, ainda, que as células as quais expressam LMP-1 e ZEBRA estavam presentes em granulomas periapicais, porém ausentes em tecidos gengivais saudáveis, sugerindo que o EBV está relacionado a inflamação periapical. Além disso, o estudo mostrou que o Fusobacterium nucleatum presente nas lesões pode induzir o EBV latente a se tornar lítico (Himi et al., 2020). Uma vez que o vírus é reativado se torna crucial o desenvolvimento da resposta imunológica inata e o desenvolvimento de doenças (Tabtieng \& Gaglia, 2018), desta forma a reativação do vírus pode agravar a inflamação 
periapical.

A reação inflamatória dentro dos tecidos perirradiculares é uma consequência da interação entre os microrganismos, seus fatores de virulência e a resposta imune do hospedeiro. Em resposta a estímulos infecciosos, uma variedade de células imunes hospedeiras na área periapical produzem citocinas pró-inflamatórias responsáveis pela reabsorção do osso alveolar periapical (Nair, 2004). A ativação das citocinas TNF- $\alpha$ e IL-1 $\beta$ estão estritamente relacionadas a fase lítica do EBV, assim como os casos de dor endodôntica e a ativação das células clásticas, responsáveis pela destruição óssea periapical. Neste sentido, é possível relacionar o EBV com a maior patogenicidade na periodontite apical e consequentemente com a reabsorção óssea periapical.

Guilherme et al. (2011) observaram em uma pequena amostra, que a infecção por EBV avaliada a partir da saliva não interferiu no sucesso do tratamento endodôntico, contudo, mais estudos avaliando o sucesso da terapia endodôntica em pacientes acometidos de EBV precisam ser realizados, uma vez que a resposta imunológica e inflamatória desencadeada pelo vírus são as mesmas envolvidas no desenvolvimento da periodontite apical.

\subsection{Citomegalovírus humano}

O citomegalovírus humano (HCMV) é o quinto membro da família Herpes vírus humano, conhecido por causar doenças clínicas, variando entre infecção assintomática e formas graves, podendo ser fatal em pacientes imunocomprometidos (Dioverti \& Razonable, 2016). A prevalência do vírus é alta na população em geral, com incidência acima de 50\% (Bate et al., 2010). A idade e fatores socioeconômicos podem aumentar sua prevalência, aproximando-se de $100 \%$ em adultos de países em desenvolvimento (Lanzieri et al., 2015). O vírus pode ser adquirido ao decorrer da vida por meio do contato do hospedeiro com fluidos corporais como saliva, lágrimas, urina, fezes, leite materno e sêmen de indivíduos infectados (Mosca et al., 2001).

A latência e possibilidade de reativação viral representa uma preocupação constante. HCMV pode permanecer em estado latente durante toda a vida do hospedeiro, alojando-se em diversas células, incluindo células progenitoras e hematopoiéticas, onde o vírus pode se multiplicar e ser transportado para diversos locais do corpo, através de monócitos/macrófagos e células dendríticas (Dupont \& Reeves, 2016; Plachter et al., 1996). Devido a capacidade de alcançar áreas distantes do local da infecção, o citomegalovírus foi associado a infecções na cavidade oral, incluindo os tecidos periapicais (Contreras et al., 1999).

$\mathrm{Na}$ endodontia, o primeiro relato da influência do HCMV na doença periapical foi descrita por Sabeti et al., (2003b), sugerindo o aparecimento ou exacerbação de sintomas clínicos em presença do vírus na infecção endodôntica. Os vírus estimulam o aumento da expressão de citocinas pró-inflamatórias e imunorreguladoras pelas células hospedeiras (Sabeti et al., 2012). A incorporação do HCMV na infecção endodôntica induz alterações nas reações imunes, como por exemplo a inibição da expressão de proteínas transmembranas (CD178), desfavorecendo a resposta do hospedeiro no controle ou eliminação da infecção viral e bacteriana (Sabeti et al., 2009). Além disso, maiores níveis de expressão de citocinas inflamatórias foram correlacionados a presença de vírus na infecção endodôntica, levando a mudanças desfavoráveis na defesa periapical do hospedeiro (Sabeti et al., 2012).

Existe uma associação relevante entre casos sintomáticos e a presença de vírus na infecção endodôntica, as espécies mais comuns identificadas foram o Epstein-Barr e o HCMV (Jakovljevic \& Andric, 2014). Além disso, a ação conjunta de patógenos bacterianos e virais está associada às formas mais graves da doença periapical, incluindo sintomatologia dolorosa e lesões de tamanhos maiores (Hernadi et al., 2010; Sabeti et al., 2003b). Outro fator importante é o aumento da expressão de RANKL na infecção endodôntica associada ao HCMV e EBV, sugerindo a associação com o aumento das lesões periapicais (Yildirim et al., 2006).

Um estudo clínico com análise por RT-PCR (Reverse Transcription-Polymerase Chain Reaction) destacou a presença 
do HCMV em casos de periodontite apical sintomática e assintomática em comparação com EBV (Yazdi et al., 2008). Dessa forma, após a análise de 28 amostras de pacientes sintomáticos, o HCMV foi identificado em 15 destas (53,6\%), enquanto o EBV em apenas $2(7,2 \%)$. Houve também a prevalência na identificação de HCMV nas amostras de lesões assintomáticas.

\subsection{HIV}

O vírus da imunodeficiência humana (HIV) interfere na ação do sistema imunológico contra agentes agressores que atacam o organismo do indivíduo impedindo-o de combater essas infecções. Sendo assim, pacientes com a Síndrome da Imunodeficiência Adquirida (AIDS) causada pelo vírus HIV foram correlacionados por sua função imunológica comprometida e a resposta do tratamento endodôntico de dentes com lesão periapical (Levine et al., 2001; Quesnell et al., 2005).

O hospedeiro ao ser infectado pelo vírus reage por meio de respostas imunes inatas e adaptativas buscando um equilíbrio entre promover respostas de citocinas antivirais e limitar o dano tecidual devido sua atuação direta na destruição celular ou por meio das reações imunes do hospedeiro (Vigueras et al., 2016).

O estadiamento clínico do HIV é observado por meio da presença de infecções oportunistas, contagem de CD4+ e a carga viral. A proteína CD4+ está presente na superfície celular do linfócito T, e por meio dela a glicoproteína gp120 do envelope viral faz sua ligação que resulta na replicação do vírus e eventualmente morte celular. Um dos sinais primários da AIDS é a depleção de células $T$, que apresentam um significante papel na resolução das lesões periapicais, podendo ter relação entre a presença do vírus HIV e a cura endodôntica (Aminoshariae et al., 2017). Além das células T, os macrófagos, monócitos e fibroblastos da polpa dentária também são alvos do vírus HIV, entretanto, apresentam maior resistência à apoptose induzido pelo vírus, atuando como um reservatório de replicação viral (Glick et al., 1991; Levine et al., 2001).

As células T participam da defesa imunológica e exercem influência sobre as atividades dos macrófagos. Quando há infecção alteram-se as funções, como produção de citocinas, quimiotaxia, função celular acessória e atividade microbicida (Levine et al., 2001). A produção de citocinas faz parte do desenvolvimento imunológico, porém a produção inapropriada desses mediadores pró-inflamatórios estimulam a reabsorção óssea e inibem a formação óssea reparadora. Dentre as principais citocinas pró-inflamatórias liberadas no processo a IL-1 desempenha um importante papel na ativação de osteoclastos, na inibição do reparo ósseo e consequentemente na patogênese das lesões periapicais (Levine et al., 2001).

Um estudo realizado por Cooper (1993) avaliou em curto prazo (3 meses) possíveis complicações clínicas de pacientes infectados com HIV. Assim, em 48 pacientes, sendo 32 pacientes HIV positivo e 16 HIV negativo foi realizada a avaliação do sucesso clínico após o tratamento endodôntico por meio de sinais e sintomas clínicos e radiográficos, concluindo que pacientes soropositivos ao HIV comparado aos pacientes saudáveis não apresentaram complicações pós-tratamento a curto prazo (Cooper, 1993).

Estudos clínicos buscaram avaliar diferenças entre a regressão da lesão da periodontite apical por meios de sinais radiográficos de pacientes portadores do vírus da imunodeficiência humana e pacientes saudáveis sem comprometimento sistêmicos (Alley et al., 2008; Quesnell et al., 2005; Tootla \& Owen, 2012). Concluindo não apresentar diferenças estatísticas significantes no prognóstico clínico e radiográfico das lesões periapicais entre pacientes HIV+ e pacientes saudáveis após a terapia endodôntica (Aminoshariae et al., 2017; Quesnell et al., 2005).

Um trabalho feito por de Brito et al. (2015) avaliou o perfil imunológico das infecções endodônticas de 20 pacientes saudáveis e 23 portadores de HIV por meio das células e expressão gênica do fluído intersticial periapical. Utilizando a análise RT-PCR foram observados em ambos os grupos o aumento das células T CD4+ CD28+ e CD8+, provavelmente em decorrência da terapia antirretroviral altamente ativa (HAART). Observaram também em pacientes HIV- o aumento da expressão de IL-10 e CXCR4 e diminuição de citocinas pró-inflamatórias, corroborando com o trabalho de Levine et al. (2001) no qual a IL-10 foi encontrada em maior nível em pacientes saudáveis do que pacientes HIV+. Enquanto em pacientes HIV+ 
houve um aumento nas citocinas IFN-y, IL-1 $\beta$, TNF- $\alpha$ e IL-17A e nas quimiocinas CCL-2, CX R4 e CCR5 (de Brito et al., 2015; Levine et al., 2001). Os resultados do trabalho realizado por de Brito et al. (2015) sugerem que em pacientes HIV-após a desinfecção antibacteriana durante o tratamento endodôntico é gerado uma resposta anti-inflamatória, enquanto nos pacientes HIV+ é mantida uma resposta pró-inflamatória na região periapical.

Uma resposta inadequada das citocinas pró-inflamatórias na região periapical ativam a atividade osteoclástica estimulando a reabsorção óssea e inibindo o reparo da lesão periapical (Levine et al., 2001). Análises de sinais e sintomas clínicos e radiográficos após o tratamento endodôntico mostraram alta taxa de sucesso não havendo diferença de reparo e prognóstico entre pacientes saudáveis e pacientes HIV+ (Aminoshariae et al., 2017; Cooper, 1993; Quesnell et al., 2005; Suchina et al., 2006). No entanto, foi observado que as citocinas liberadas no paciente HIV+ mantém uma resposta próinflamatória após o preparo biomecânico do canal radicular sugerindo a inibição do reparo ósseo da lesão periapical. Entretanto, a explicação para pacientes HIV+ apresentarem o reparo ósseo esperado da mesma forma que pacientes HIV- é hipotetizado por meio das quimiocinas CCL-2 e CXCR4, capazes de induzir uma mudança pró-inflamatórias para inflamatória conduzindo a neoformação óssea da região (de Brito et al., 2015).

\subsection{Um olhar sobre a pluralidade das infecções}

Há determinadas situações em que o especialista lança mão de todo seu conhecimento e arsenal endodôntico, bem como as condições anatômicas dos canais radiculares e a saúde sistêmica do paciente são favoráveis a um quadro de sucesso da terapia endodôntica, porém o insucesso surge de forma imprevisível. Seria este um caso de pluralidade da infecção? E seria a associação de bactérias, fungos e vírus responsáveis pelo insucesso da terapia? Esses questionamentos são importantes para o clínico especialista, uma vez que uma anamnese bem detalhada e a investigação por exames laboratoriais e histológicos dos tecidos endo-periodontais podem o levar a uma resposta e consequentemente a terapia mais adequada para o sucesso do tratamento endodôntico.

\section{Conclusão}

Os achados não estabelecem uma relação causa-efeito entre a presença de vírus nos tecidos periapicais e a patogenicidade da infecção presente, no entanto, mais estudos devem ser realizados para afirmar o potencial viral nos tecidos periapicais, uma vez que a literatura mostra uma resposta imunológica na periodontite apical desencadeada por vírus na fase lítica, semelhante a observada a outros patógenos, sendo capaz de exacerbar a resposta inflamatória, aumentar a reabsorção óssea e ainda interferir no reparo dos tecidos periapicais.

As dificuldades em estudar os vírus são principalmente devido ao alto custo de testes laboratoriais e pela sensibilidade dos resultados. Apesar dessas barreiras, a comunidade científica deve direcionar os estudos futuros para análises moleculares a fim de responder qual o papel da infecção viral na expressão de mediadores químicos e celulares envolvidos na destruição dos tecidos periapicais capazes de interferir no reparo.

\section{Agradecimentos}

Agradecemos ao apoio da Coordenação de Aperfeiçoamento de Pessoal de Nível Superior - Brasil (CAPES) - Código de Financiamento 001. 


\section{Referências}

Alley, B. S., Buchanan, T. H., \& Eleazer, P. D. (2008). Comparison of the success of root canal therapy in HIV/AIDS patients and non-infected controls. General Dentistry, 56(2), 155-157. https://www.researchgate.net/publication/5504826_Comparison_of_the_success_of_root_canal_therapy_in _HIVAIDS_patients_and_non-infected_controls

Aminoshariae, A., Kulild, J. C., Mickel, A., \& Fouad, A. F. (2017). Association between systemic diseases and endodontic outcome: a systematic review. Journal of Endodontics, 43(4), 514-519. https://doi.org/10.1016/j.joen.2016.11.008

Bate, S. L., Dollard, S. C., \& Cannon, M. J. (2010). Cytomegalovirus seroprevalence in the United States: the national health and nutrition examination surveys, 1988-2004. Clinical Infectious Diseases, 50(11), 1439-1447. https://doi.org/10.1086/652438

Chen, C., Feng, P., \& Slots, J. (2020). Herpesvirus-bacteria synergistic interaction in periodontitis. Periodontology 2000, 82(1), 42-64. https://doi.org/10.1111/prd.12311

Cohen, J. I. (2000). Epstein-Barr virus infection. New England Journal of Medicine, 343(7), 481-492. 10.1056/NEJM200008173430707

Contreras, A., Zadeh, H. H., Nowzari, H., \& Slots, J. (1999). Herpesvirus infection of inflammatory cells in human periodontitis. Oral Microbiology and Immunology, 14(4), 206-212. https://doi.org/10.1034/j.1399-302X.1999.140402.X

Cooper, H. (1993). Root canal treatment on patients with HIV infection. International Endodontic Journal, 26(6), 369-371. https://doi.org/10.1111/j.13652591.1993.tb00771.x

De Brito, L. C. N., Teles, F. R., Teles, R. P., Nogueira, P. M., Vieira, L. Q., \& Ribeiro Sobrinho, A. P. (2015). Immunological profile of periapical endodontic infections from HIV- and HIV+ patients. International Endodontic Journal, 48(6), 533-541. https://doi.org/10.1111/iej.12345

Dioverti, M. V., \& Razonable, R. R. (2016). Cytomegalovirus. Microbiology Spectrum, 4(4), 10.1128/microbiolspec.DMIH2-0022-2015. https://doi.org/10.1128/microbiolspec.DMIH2-0022-2015

Dupont, L., \& Reeves, M. B. (2016). Cytomegalovirus latency and reactivation: recent insights into an age old problem. Reviews in Medical Virology, 26(2), 75-89. https://doi.org/10.1002/rmv.1862

Elkins, D. A., Torabinejad, M., Schmidt, R. E., Rossi, J. J., \& Kettering, J. D. (1994). Polymerase chain reaction detection of human immunodeficiency virus DNA in human periradicular lesions. Journal of Endodontics, 20(8), 386-388. https://doi.org/10.1016/S0099-2399(06)80296-7

Epstein, M. A. (1964). Virus particles in cultured lymphoblasts from Burkitt's lymphoma. Lancet, 1(7335), 702-703. https://doi.org/10.1016/S01406736(64)91524-7

Ferreira, D. C., Paiva, S. S., Carmo, F. L., Rôças, I. N., Rosado, A. S., Santos, K. R., \& Siqueira Jr, J. F. (2011). Identification of herpesviruses types 1 to 8 and human papillomavirus in acute apical abscesses. Journal of Endodontics, 37(1), 10-16. https://doi.org/10.1016/j.joen.2010.09.009

Glick, M., Trope, M., Bagasra, O., \& Pliskin, M. E. (1991). Human immunodeficiency virus infection of fibroblasts of dental pulp in seropositive patients. Oral Surgery, Oral Medicine, and Oral Pathology, 71(6), 733-736. https://doi.org/10.1016/0030-4220(91)90284-J

Gomes, B. P. F. D. A., \& Herrera, D. R. (2018). Etiologic role of root canal infection in apical periodontitis and its relationship with clinical symptomatology. Brazilian Oral Research, 32(suppl 1), e69. http://dx.doi.org/10.1590/1807-3107bor-2018.vol32.0069

Green, M., \& Michaels, M. G. (2013). Epstein-Barr virus infection and posttransplant lymphoproliferative disorder. American Journal of Transplantation, 13(s3), 41-54. https://doi.org/10.1111/ajt.12004

Guilherme, B. P., Ferreira, D. C., Rôças, I. N., Provenzano, J. C., Santos, K. R., \& Siqueira Jr, J. F. (2011). Herpesvirus carriage in saliva and posttreatment apical periodontitis: searching for association. Oral Surgery, Oral Medicine, Oral Pathology, Oral Radiology, and Endodontology, 112(5), 678-683. https://doi.org/10.1016/j.tripleo.2011.05.003

Guimarães, F., Pavelski, M. D., Dallazen, E., de Souza Santos, A. M., Delanora, L. A., Silva, W. P. P., \& Magro Filho, O. (2021). Como identificar uma manifestação oral de Herpes-Zoster? Research, Society and Development, 10(2), e31610212617-e31610212617. https://doi.org/10.33448/rsd-v10i2.12617

Hernádi, K., Szalmás, A., Mogyorósi, R., Czompa, L., Veress, G., Csoma, E., ... \& Kónya, J. (2010). Prevalence and activity of Epstein-Barr virus and human cytomegalovirus in symptomatic and asymptomatic apical periodontitis lesions. Journal of Endodontics, 36(9), 1485-1489. https://doi.org/10.1016/j.joen.2010.06.008

Himi, K., Takeichi, O., Imai, K., Hatori, K., Tamura, T., \& Ogiso, B. (2020). Epstein-Barr virus reactivation by persistent apical periodontal pathogens. International Endodontic Journal, 53(4), 492-505. https://doi.org/10.1111/iej.13255

Holland, R., Gomes Filho, J. E., Cintra, L. T. A., Queiroz, Í. O. D. A., \& Estrela, C. (2017). Factors affecting the periapical healing process of endodontically treated teeth. Journal of Applied Oral Science, 25(5), 465-476. https://doi.org/10.1590/1678-7757-2016-0464

Jakovljevic, A., \& Andric, M. (2014). Human cytomegalovirus and Epstein-Barr virus in etiopathogenesis of apical periodontitis: a systematic review. Journal of Endodontics, 40(1), 6-15. https://doi.org/10.1016/j.joen.2013.10.001

Jakovljevic, A., Andric, M., Knezevic, A., Soldatovic, I., Nikolic, N., Karalic, D., \& Milasin, J. (2015). Human cytomegalovirus and Epstein-Barr virus genotypes in apical periodontitis lesions. Journal of Endodontics, 41(11), 1847-1851. https://doi.org/10.1016/j.joen.2015.08.027

Jakovljevic, A., Andric, M., Nikolic, N., Coric, V., Krezovic, S., Carkic, J., \& Milasin, J. (2018). Levels of oxidative stress biomarkers and bone resorption regulators in apical periodontitis lesions infected by Epstein-Barr virus. International Endodontic Journal, 51(6), 593-604. https://doi.org/10.1111/iej.12886 
Jakovljevic, A., Nikolic, N., Carkic, J., Beljic-Ivanovic, K., Soldatovic, I., Miletic, M., \& Milasin, J. (2020). Association of polymorphisms in TNF- $\alpha$, IL-1 $\beta$, GSTM and GSTT genes with apical periodontitis: is there a link with herpesviral infection? International Endodontic Journal, 53(7), 895-904. https://doi.org/10.1111/iej.13298

Jangra, S., Yuen, K. S., Botelho, M. G., \& Jin, D. Y. (2019). Epstein-Barr virus and innate immunity: Friends or foes?. Microorganisms, 7(6), 183. https://doi.org/10.3390/microorganisms 7060183

Jones, J. F., Shurin, S., Abramowsky, C., Tubbs, R. R., Sciotto, C. G., Wahl, R., \& Sklar, J. (1988). T-cell lymphomas containing Epstein-Barr viral DNA in patients with chronic Epstein-Barr virus infections. New England Journal of Medicine, 318(12), 733-741. 10.1056/NEJM198803243181203

Kivity, S., Arango, M. T., Ehrenfeld, M., Tehori, O., Shoenfeld, Y., Anaya, J. M., \& Agmon-Levin, N. (2014). Infection and autoimmunity in Sjogren's syndrome: a clinical study and comprehensive review. Journal of Autoimmunity, 51, 17-22. https://doi.org/10.1016/j.jaut.2014.02.008

Köche, J. C. (2016). Fundamentos de metodologia científica. Ed. Vozes. http://www.brunovivas.com/wp-content/uploads/sites/10/2018/07/K\%C3\%B6cheJos\%C3\%A9-Carlos0D0AFundamentos-de-metodologia-cient\%C3\%ADfica-_-teoria-da0D0Aci\%C3\%AAncia-e-inicia\%C3\%A7\%C3\%A3o-\%C3\%A0pesquisa.pdf

Lanzieri, T. M., Kruszon-Moran, D., Amin, M. M., Bialek, S. R., Cannon, M. J., Carroll, M. D., \& Dollard, S. C. (2015). Seroprevalence of cytomegalovirus among children 1 to 5 years of age in the United States from the National Health and Nutrition Examination Survey of 2011 to 2012. Clinical and Vaccine Immunology, 22(2), 245-247. 10.1128/CVI.00697-14

Levine, D. F., Witherspoon, D. E., Gutmann, J. L., \& Iacopino, A. M. (2001). Interleukin-1 $\beta$ production in periradicular lesions in a human immunodeficiency virus/acquired immune deficiency syndrome model compared with a noninfected host. Journal of Endodontics, 27(8), 499-502. https://doi.org/10.1097/00004770-200108000-00001

Li, H., Chen, V., Chen, Y., Baumgartner, J. C., \& Machida, C. A. (2009). Herpesviruses in endodontic pathoses: association of Epstein-Barr virus with irreversible pulpitis and apical periodontitis. Journal of Endodontics, 35(1), 23-29. https://doi.org/10.1016/j.joen.2008.09.017

Ludke, M. \& Andre, M. E. D. A. (2013). Pesquisa em educação: abordagens qualitativas. Ed. EPU.

Luzuriaga, K., \& Sullivan, J. L. (2010). Infectious mononucleosis. The New England Journal of Medicine, 362(21), 1993-2000. https://doi.org/10.1056/NEJMcp1001116

Márton, I. J., \& Kiss, C. (2014). Overlapping protective and destructive regulatory pathways in apical periodontitis. Journal of Endodontics, 40(2), 155-163. https://doi.org/10.1016/j.joen.2013.10.036

Mochanko, K., Fejes, M., Breazavscek, D. M., Suarez, A., \& Bachmann, A. E. (1979). The relation between epstein-barr virus antibodies and clinical symptomatology and immunodeficiency in patients with Hodgkin's disease. Cancer, 44(6), 2065-2070. https://doi.org/10.1002/1097-0142(197912)44:6<2065: AID-CNCR2820440617>3.0.CO;2-G

Mogensen, T. H., \& Paludan, S. R. (2001). Molecular pathways in virus-induced cytokine production. Microbiology and molecular biology reviews: MMBR, 65(1), 131-150. https://doi.org/10.1128/MMBR.65.1.131-150.2001

Mosca, F., Pugni, L., Barbi, M., \& Binda, S. (2001). Transmission of cytomegalovirus. The Lancet, 357(9270), 1800. https://doi.org/10.1016/S01406736(00)04914-X

Nair, P. R. (2004). Pathogenesis of apical periodontitis and the causes of endodontic failures. Critical Reviews in Oral Biology \& Medicine, 15(6), 348-381. https://doi.org/10.1177/154411130401500604

Nowalk, A., \& Green, M. (2016). Epstein-Barr Virus. Microbiology Spectrum, 4(3), 10.1128/microbiolspec.DMIH2-0011-2015. https://doi.org/10.1128/microbiolspec.DMIH2-0011-2015

Ozbek, S. M., Ozbek, A., \& Demiray, T. (2016). Prevalence of several herpesviruses and human papillomavirus in acute apical abscesses. International Endodontic Journal, 49(6), 519-525. https://doi.org/10.1111/iej.12482

Pereira A. S. et al. (2018). Metodologia da pesquisa científica. UFSM. https://repositorio.ufsm.br/bitstream/handle/1/15824/Lic_Computacao_MetodologiaPesquisa-Cientifica.pdf?sequence $=1$

Plachter, B., Sinzger, C., \& Jahn, G. (1996). Cell types involved in replication and distribution of human cytomegalovirus. Advances in Virus Research, 46, 195-261. https://doi.org/10.1016/S0065-3527(08)60073-1

Quesnell, B. T., Alves, M., Hawkinson Jr, R. W., Johnson, B. R., Wenckus, C. S., \& BeGole, E. A. (2005). The effect of human immunodeficiency virus on endodontic treatment outcome. Journal of Endodontics, 31(9), 633-636. https://doi.org/10.1097/01.don.0000157985.88883.81

Ricucci, D., Lin, L. M., \& Spångberg, L. S. (2009). Wound healing of apical tissues after root canal therapy: a long-term clinical, radiographic, and histopathologic observation study. Oral Surgery, Oral Medicine, Oral Pathology, Oral Radiology, and Endodontology, 108(4), 609-621. https://doi.org/10.1016/j.tripleo.2009.05.028

Sabeti, M., Daneshmand, A., Simon, J. H., \& Slots, J. (2009). Cytomegalovirus-infected inflammatory cells in dental periapical lesions. Oral Microbiology and Immunology, 24(5), 434-436. https://doi.org/10.1111/j.1399-302X.2009.00540.x

Sabeti, M., Kermani, V., Sabeti, S., \& Simon, J. H. (2012). Significance of human cytomegalovirus and Epstein-Barr virus in inducing cytokine expression in periapical lesions. Journal of Endodontics, 38(1), 47-50. https://doi.org/10.1016/j.joen.2011.09.026

Sabeti, M., Simon, J. H., Nowzari, H., \& Slots, J. (2003a). Cytomegalovirus and Epstein-Barr virus active infection in periapical lesions of teeth with intact crowns. Journal of Endodontics, 29(5), 321-323. https://doi.org/10.1097/00004770-200305000-00002 
Research, Society and Development, v. 10, n. 3, e14210313134, 2021

(CC BY 4.0) | ISSN 2525-3409 | DOI: http://dx.doi.org/10.33448/rsd-v10i3.13134

Sabeti, M., Valles, Y., Nowzari, H., Simon, J. H., Kermani-Arab, V., \& Slots, J. (2003b). Cytomegalovirus and Epstein-Barr virus DNA transcription in endodontic symptomatic lesions. Oral Microbiology and Immunology, 18(2), 104-108. https://doi.org/10.1034/j.1399-302X.2003.00055.x

Sawada, S., Takei, M., Inomata, H., Nozaki, T., \& Shiraiwa, H. (2007). What is after cytokine-blocking therapy, a novel therapeutic target-synovial EpsteinBarr virus for rheumatoid arthritis. Autoimmunity Reviews, 6(3), 126-130. https://doi.org/10.1016/j.autrev.2006.08.014

Saygun, I., Yapar, M., Özdemir, A., Kubar, A., \& Slots, J. (2004). Human cytomegalovirus and Epstein-Barr virus type 1 in periodontal abscesses. Oral Microbiology and Immunology, 19(2), 83-87. https://doi.org/10.1046/j.0902-0055.2002.00118.x

Shindell, E. (1962). Studies on the possible presence of a virus in subacute and chronic periapical granulomas. Oral surgery, Oral Medicine, and Oral Pathology, 15(11), 1382-1384. https://doi.org/10.1016/0030-4220(62)90359-6

Siqueira Jr, J. F., \& Rôças, I. N. (2008). Clinical implications and microbiology of bacterial persistence after treatment procedures. Journal of Endodontics, 34(11), 1291-1301. https://doi.org/10.1016/j.joen.2008.07.028

Slots, J. (2005). Herpesviruses in periodontal diseases. Periodontology 2000, 38(1), 33-62. https://doi.org/10.1111/j.1600-0757.2005.00109.x

Slots J. (2010). Herpesviral-bacterial interactions in periodontal diseases. Periodontology 2000, 52(1), 117-140. https://doi.org/10.1111/j.16000757.2009.00308.x

Slots, J., Sabeti, M., \& Simon, J. H. (2003). Herpesviruses in periapical pathosis: an etiopathogenic relationship? Oral Surgery, Oral Medicine, Oral Pathology, Oral Radiology, and Endodontics, 96(3), 327-331. https://doi.org/10.1016/s1079-2104(03)00352-4

Suchina, J. A., Levine, D., Flaitz, C. M., Nichols, C. M., \& Hicks, M. J. (2006). Retrospective clinical and radiologic evaluation of nonsurgical endodontic treatment in human immunodeficiency virus (HIV) infection. The Journal of Contemporary Dental Practice, 7(1), 1-8. 10.5005/jcdp-7-1-1

Tabtieng, T., \& Gaglia, M. M. (2018). Emerging proviral roles of caspases during lytic replication of gammaherpesviruses. Journal of Virology, 92(19). 10.1128/JVI.01011-17

Tootla, S., \& Owen, C. P. (2012). A comparison of endodontic treatment outcomes between HIV-positive and HIV-negative patients. SADJ: Journal of the South African Dental Association = tydskrif van die Suid-Afrikaanse Tandheelkundige Vereniging, 67(7), 322-325. https://journals.co.za/doi/10.10520/EJC143613

Vigueras, S. H., Zúniga, M. D., Jané-Salas, E., Navarrete, L. S., Segura-Egea, J. J., Velasco-Ortega, E., \& López-López, J. (2016). Viruses in pulp and periapical inflammation: a review. Odontology, 104(2), 184-191. 10.1007/s10266-015-0200-y

Yazdi, K. A., Sabeti, M., Jabalameli, F., Eman eini, M., Kolahdouzan, S. A., \& Slots, J. (2008). Relationship between human cytomegalovirus transcription and symptomatic apical periodontitis in Iran. Oral Microbiology and Immunology, 23(6), 510-514. https://doi.org/10.1111/j.1399-302X.2008.00471.x

Yildirim, S., Yapar, M., Kubar, A., \& Slots, J. (2006). Human cytomegalovirus, Epstein-Barr virus and bone resorption-inducing cytokines in periapical lesions of deciduous teeth. Oral Microbiology and Immunology, 21(2), 107-111. https://doi.org/10.1111/j.1399-302X.2006.00268.x 